\title{
What is the impact of metabolic syndrome and its components on reflux esophagitis? A cross-sectional study
}

Yi-Hsuan Hsieh ${ }^{1}$, Mei-Fong Wu ${ }^{1,2}$, Pei-Yu Yang ${ }^{3}$, Wei-Cheng Liao ${ }^{4}$, Yao-Hsuan Hsieh ${ }^{1,5}$, Yu-Jun Chang ${ }^{6}$ and I-Ching $\operatorname{Lin}^{1,7,8^{*}}$ (D)

\begin{abstract}
Background: The prevalence rate of reflux esophagitis (RE) in Asia, including Taiwan, has increased dramatically in recent years. However, few studies have discussed on its relationship with metabolic syndrome (MetS). This study aimed to evaluate the correlation between RE and MetS and its components.
\end{abstract}

Methods: We conducted a cross-sectional study during 2013 to 2014 in Taiwan. A total of 4895 subjects who completed upper gastrointestinal endoscopy at the Health Examination Center of Changhua Christian Hospital were enrolled. RE was defined according to the upper gastrointestinal endoscopic findings and MetS was defined according to the Taiwanese criteria. Univariate and multivariate logistic regression analyses were applied to calculate odds ratios and $95 \%$ confidence intervals for each variable to assess the associated features for RE. We analyzed the relationship between the number of MetS components and the severity of RE using the chi-square test for trend.

Results: The prevalence rates of MetS and RE were respectively 28.5 and 59.6\%. According to univariate logistic regression analysis, MetS was significantly associated with $\mathrm{RE}$ and remained a positive association in multivariate logistic regression analysis (adjusted $\mathrm{OR}^{\beta}=1.251 ; 95 \% \mathrm{Cl}=1.071-1.462 ; p=0.005$ ). Furthermore, among the five MetS components, elevated blood pressure (adjusted $\mathrm{OR}^{\Upsilon}=1.163 ; 95 \% \mathrm{Cl}=1.023-1.323 ; p=0.021$ ), abdominal obesity (adjusted $\mathrm{OR}^{\Upsilon}=1.173 ; 95 \% \mathrm{Cl}=1.020-1.349 ; p=0.026$ ) and hyperglycemia (adjusted $\mathrm{OR}^{\Upsilon}=1.306 ; 95 \% \mathrm{Cl}=1$. $142-1.495 ; p<0.001$ ) were positively associated with the presence of RE. A weak association was also found between elevated triglycerides and RE after adjusting for age and gender (adjusted $\mathrm{OR}^{\mathrm{a}}=1.171 ; 95 \% \mathrm{Cl}=1.022-1$. 343; $p=0.023$ ). Reduced high-density lipoprotein cholesterol showed no significant difference between groups with and without RE. Older age ( $\geq 65$ years), male gender, higher body mass index, higher uric acid, smoking, alcohol drinking, and hiatal hernia were found to be significant associated factors for RE. In addition, a dose-response relation between the number of MetS components and the presence of RE was demonstrated in the multivariate analysis. Furthermore, we performed a trend analysis and found the severity of RE got worse as the number of MetS components increased $(p<0.001)$

Conclusion: This study suggests that MetS is significantly related to the presence and the severity of RE. Keywords: Reflux esophagitis, Gastroesophageal reflux, Metabolic syndrome

\footnotetext{
* Correspondence: licypy01@gmail.com

${ }^{1}$ Department of Family Medicine, Changhua Christian Hospital, No. 135, St. Nan-Xiao, Changhua City 500, Taiwan

${ }^{7}$ School of Medicine, Chung Shan Medical University, Taichung City, Taiwan

Full list of author information is available at the end of the article
}

(c) The Author(s). 2019 Open Access This article is distributed under the terms of the Creative Commons Attribution 4.0 International License (http://creativecommons.org/licenses/by/4.0/), which permits unrestricted use, distribution, and reproduction in any medium, provided you give appropriate credit to the original author(s) and the source, provide a link to the Creative Commons license, and indicate if changes were made. The Creative Commons Public Domain Dedication waiver (http://creativecommons.org/publicdomain/zero/1.0/) applies to the data made available in this article, unless otherwise stated. 


\section{Background}

Reflux esophagitis (RE) has become a major public health issue in Asia. A low prevalence rate of 3.3\% was reported in an epidemiological report in Singapore by Kang et al. in 1993 [1], however, subsequent studies have reported a rapid increase in Asian populations, ranging from 4.3 to $37.8 \%[2,3]$.

$\mathrm{RE}$ is defined as visible esophageal mucosal damage on endoscopy $[4,5]$. RE results from the abnormal retrograde flow of gastric contents into the esophagus [5]. RE has been hypothesized to be a multifactorial process, including an abnormal frequency of gastroesophageal reflux, delayed esophageal clearance, delayed gastric emptying, and transient lower esophageal sphincter tone relaxation [6-8]. RE can cause serious complications if untreated for a prolonged period, including esophageal stricture, Barrett's esophagus, and esophageal adenocarcinoma $[4,5]$.

Previous studies have reported positive associations between RE and the following associated factors: older age, male gender, smoking, alcohol consumption, and hiatal hernia, and a negative association between RE and Helicobacter pylori (H. pylori) infection [9-13]. Obesity is also known to play an important role in $\operatorname{RE}[9,10,14-16]$. Further evidences have demonstrated that abdominal obesity, which is the core component of metabolic syndrome (MetS), may be a stronger predictor of RE than obesity [10, 11, 16-20]. MetS is generally recognized to be a combination of metabolic abnormalities, including abdominal obesity, hypertension, hyperglycemia, reduced high-density lipoprotein cholesterol (HDL-C), and elevated triglycerides (TG) [21, 22]. Visceral fat accumulation and insulin resistance are currently thought to be the predominant causes of MetS [6, 21, 23]. Patients with MetS have a high risk of cardiovascular disease, diabetes mellitus, and other atherosclerotic diseases [16, 23, 24]. A retrospective case-control study in China in 2010 found that a high waist-hip ratio, hyperglycemia, hypertriglyceridemia, and MetS were the associated factors for RE, and that HDL-C was associated with a reduced risk of RE in men [25]. Another study in Taiwan in 2017 also found a positive association between MetS and RE [26]. These findings suggest that there may be pathogenetic links between RE and MetS [10, 12, 27].

With the increasing levels of obesity and Western diet in Taiwan, it is important to understand the relationship between MetS and RE and further explore the risk factors for RE. Identification of modifiable risk factors and further prevent RE and MetS earlier in healthy people in Taiwan is an important task. However, there was lack of study related to the correlation between the two diseases in Taiwanese. Therefore, the primary aim of this study was to assess the relationship of MetS and its components and RE. The secondary aim was to investigate the association between the number of MetS components and the severity of RE. We hypothesized that there is a positive association between the two diseases in a Taiwanese population.

\section{Methods \\ Study design and study population}

In this retrospective cross-sectional study, we enrolled the study population from the Health Examination Center of Changhua Christian Hospital, Changhua City, Taiwan. In total, 5630 subjects who underwent upper gastrointestinal endoscopy at the Health Examination Center from January-2013 to December-2014 were enrolled. Participants with incomplete data $(n=503)$, repeated examinations $(n=$ $214)$, and a clinical history of gastrointestinal surgery $(n=18)$ were excluded. Finally, a total of 4895 participants were recruited for the analysis (Fig. 1). The study protocol was approved by the Ethics Committee of Changhua Christian Hospital (CCH IRB No: 150408).

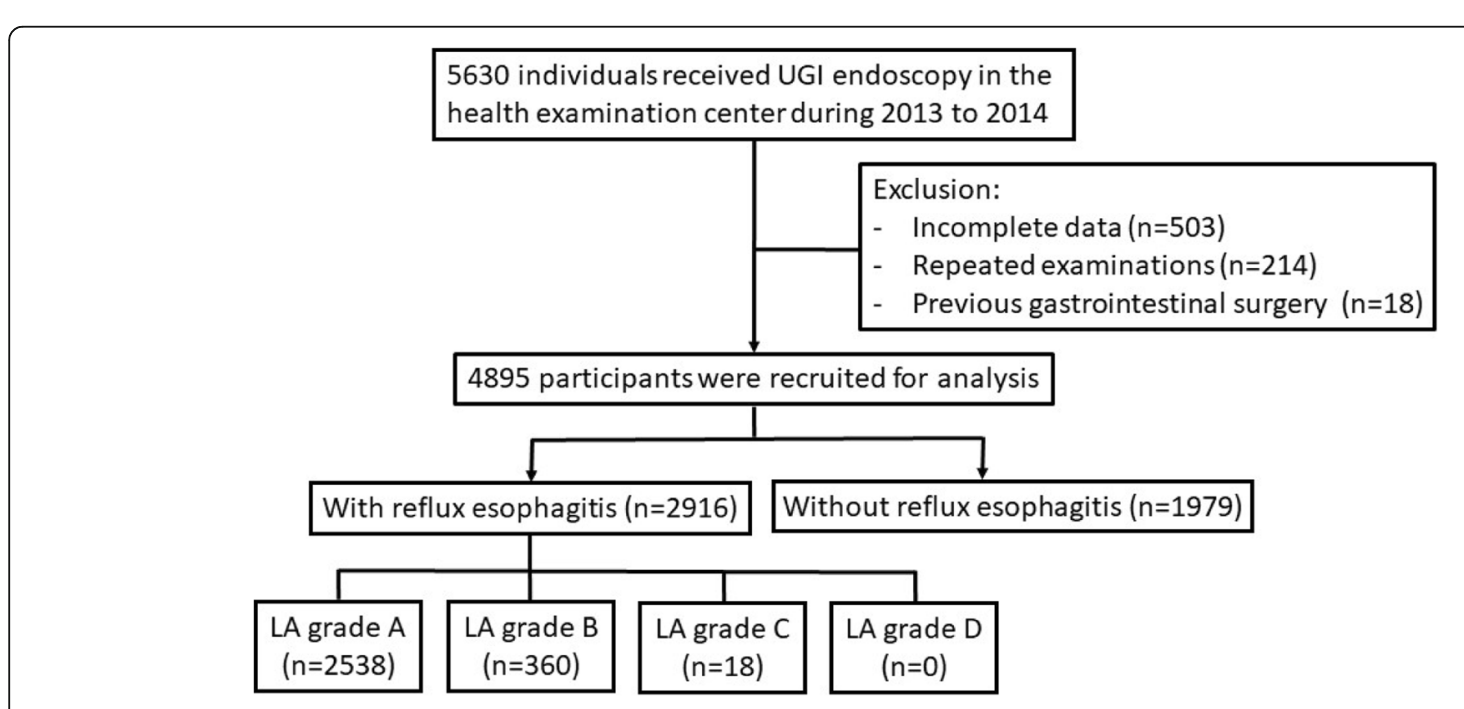

Fig. 1 Flow chart of the study design. Abbreviations: UGl upper gastrointestinal, LA grade Los Angeles classification of esophagitis 


\section{Data collection}

All 4895 participants underwent upper gastrointestinal endoscopy by experienced gastroenterologists. In addition, all of the enrolled subjects completed a questionnaire of basic data, including age, gender, self-reported medical history (including hypertension, diabetes mellitus, hyperlipidemia, and gastrointestinal malignancy), and self-reports of smoking (yes or no), alcohol consumption (yes or no), and betel nut chewing (yes or no). We did not investigate the type or quantity of smoking, alcohol and betel nut consumption in the questionnaire.

All of the participants received physical examinations and measurements of body height, body weight, waist circumference, blood pressure (BP), and body fat percentage. Body mass index (BMI) was calculated as $\mathrm{kg} / \mathrm{m}^{2}$. The physical examinations were performed by experienced family medicine physicians. Waist circumference (to the nearest $0.1 \mathrm{~cm}$ ) was measured according to the World Health Organization recommendations: as the midpoint between the lower margin of the least palpable rib and the top of the iliac crest in a standing position [28]. The brachial systolic blood pressure (SBP) and diastolic blood pressure (DBP) were obtained in a sitting position after at least $10 \mathrm{~min}$ of resting. We used a body composition analyzer X-Scan plus II (Jawon Medical, Korea) to measure the body fat percentage. In addition, all patients received laboratory blood tests, including fasting plasma glucose (FPG), glycosylated hemoglobin (HbA1C), total cholesterol (TC), TG, low-density lipoprotein cholesterol (LDL-C), and HDL-C. The blood samples were obtained after an overnight fast of at least $8 \mathrm{~h}$.

\section{Diagnostic criteria}

\section{Reflux esophagitis}

RE was defined according to the upper gastrointestinal endoscopic findings. We divided all of the recruited individuals into two groups: those with RE and those without RE. Furthermore, the subjects with RE were classified into four grades according to the endoscopic finding of the severity of RE. We used the Los Angeles classification of esophagitis (LA) to define the severity of RE as follows [29]:

(1) Grade A: one or several mucosal breaks limited to the mucosal folds and each $<5 \mathrm{~mm}$ in length.

(2) Grade B: one or several mucosal breaks limited to the mucosal folds and at least one mucosal break $\geq 5 \mathrm{~mm}$ in length but not continuous between the tops of two mucosal folds.

(3) Grade C: at least one mucosal break extending over two or more mucosal folds, involving $<75 \%$ of the circumference.

(4) Grade D: One or more mucosal breaks involving $\geq 75 \%$ of the circumference.

\section{Hiatal hernia}

The diagnosis of hiatal hernia was based on the endoscopic finding, which showed a herniation of abdominal organs through esophageal hiatus of diaphragm into the chest.

\section{Helicobacter. Pylori infection}

The diagnosis of $H$. pylori infection was based on the rapid urease test. In the process of performing an upper gastrointestinal endoscopy, if the gastroenterologist found a gastric ulcer lesion and felt it was necessary, he/she would perform a mucosa biopsy for rapid urease test.

\section{Metabolic syndrome}

The Taiwanese criteria for MetS was established based on the 2005 revised National Cholesterol Education Program Adult Treatment Panel III (NCEP ATP III) recommendations for Asians [21]. MetS was defined as the presence of three or more of the following five risk factors:

(1) Abdominal obesity: defined as a waist circumference $\geq 90 \mathrm{~cm}$ in males and $\geq 80 \mathrm{~cm}$ in females.

(2) Elevated TG: serum TG $\geq 150 \mathrm{mg} / \mathrm{dL}$ or on drug treatment for elevated TG.

(3) Reduced HDL-C: serum HDL-C $<40 \mathrm{mg} / \mathrm{dL}$ in males and $<50 \mathrm{mg} / \mathrm{dL}$ in females or on drug treatment for reduced HDL-C.

(4) Elevated BP: SBP $\geq 130 \mathrm{mmHg}$ or DBP $\geq 85 \mathrm{mmHg}$ or receiving treatment for hypertension.

(5) Hyperglycemia: FPG $\geq 100 \mathrm{mg} / \mathrm{dL}$ or receiving treatment for diabetes mellitus.

In our study, MetS and its components were defined according to the Taiwanese criteria. Participants with a diabetes history were included in the hyperglycemia group, and those with a hypertension history were included in the elevated BP group. However, we did not include those with a history of hyperlipidemia into elevated TG group or reduced HDL-C group due to lack of information about which lipid-lowering medicine was used.

\section{Statistical analysis}

Continuous variables were presented as mean \pm standard deviation (SD) and categorical variables were presented as number $(\mathrm{N})$ with percentage (\%). We analyzed the relationship between the number of MetS components and the severity of RE using the chi-square test for trend. Univariate and multivariate logistic regression analyses were applied to calculate odds ratios (OR) and 95\% confidence intervals (CI) for each variable to assess the risk factors for RE. A $p$ value $<0.05$ was considered to be statistically significant. We used IBM Statistical Package for the Social Sciences (SPSS) version 18.0. for all statistical analyses. 


\section{Results}

A total of 4895 participants were recruited for the analysis, with a mean age of $50.1 \pm 11.2$ years. Of the 4895 participants, $58.4 \%(n=2859)$ were male and $41.6 \%(n=$ 2036) were female. The prevalence rates of MetS and RE were $28.5 \%(n=1395)$ and $59.6 \%(n=2916)$, respectively. Table 1 presented demographic characteristics and clinical parameters of the study population.

According to univariate logistic regression analysis (Table 2), older age, male gender, smoking, alcohol consumption, betel nut chewing, higher BMI, higher uric acid, hypertension history, diabetes history, H. pylori infection, hiatal hernia, elevated TG, abdominal obesity, elevated BP, hyperglycemia, and the presence of MetS were all positively related to RE. On the other hand, hyperlipidemia history, gastric ulcer, and reduced HDL-C showed no significant difference between the groups with and without RE.

Table 3 illustrated the comparison of associated features with RE by multivariate logistic regression analysis in three different models. Age and gender were adjusted for each clinical variable in the model 1 . The following variables showed positive associations with the presence of RE in the model 1: smoking (adjusted $\mathrm{OR}^{\alpha}=1.443$; 95\% CI $=1.207-$ 1.724; $p<0.001$ ), alcohol drinking (adjusted $\mathrm{OR}^{\alpha}=1.382$; 95\% CI $=1.183-1.615 ; p<0.001$ ), hypertension history (adjusted $\left.\mathrm{OR}^{\alpha}=1.201 ; 95 \% \mathrm{CI}=1.036-1.393 ; p=0.015\right)$, diabetes history (adjusted $\mathrm{OR}^{\alpha}=1.433$; 95\% CI $=1.182-1.736$; $p<0.001$ ), hiatal hernia (adjusted $\mathrm{OR}^{\alpha}=8.230$; $95 \% \mathrm{CI}=$ 2.978-22.745; $p<0.001$ ), abdominal obesity (adjusted $\mathrm{OR}^{\alpha}=$ 1.352; 95\% CI $=1.186-1.542 ; p<0.001)$, elevated TG (adjusted $\left.\mathrm{OR}^{\alpha}=1.171 ; \quad 95 \% \quad \mathrm{CI}=1.022-1.343 ; \quad p=0.023\right)$, elevated BP (adjusted $\mathrm{OR}^{\alpha}=1.197 ; 95 \% \mathrm{CI}=1.056-1.356 ; p$ $=0.005$ ), hyperglycemia (adjusted $\mathrm{OR}^{\alpha}=1.306 ; 95 \% \mathrm{CI}=$ $1.144-1.492 ; p<0.001$ ), and the presence of MetS (adjusted $\left.\mathrm{OR}^{\alpha}=1.411 ; 95 \% \mathrm{CI}=1.233-1.616 ; p=<0.001\right)$.

All variables in the model 2 (including age, gender, BMI, uric acid, smoking, alcohol drinking, hiatal hernia, and MetS) were controlled by each other. The variables that showed strong collinearity with others were excluded from model 2. The results of model 2 showed that MetS remained a significantly positive association with RE (adjusted $\left.\mathrm{OR}^{\circledR}=1.251 ; 95 \% \mathrm{CI}=1.071-1.462 ; p=0.005\right)$.

Furthermore, we conducted model 3 to assess the association between RE and the individual components of MetS. All variables in the model 3 (including age, gender, uric acid, smoking, alcohol drinking, hiatal hernia, elevated BP, abdominal obesity and hyperglycemia) were controlled by each other. The variables that showed strong collinearity with others were excluded from model 3. Among the five MetS components, elevated BP (adjusted $\mathrm{OR}^{\gamma}=1.163 ; 95 \% \mathrm{CI}=1.023-1.323 ; p=0.021$ ), abdominal obesity (adjusted $\mathrm{OR}^{\gamma}=1.173 ; 95 \% \mathrm{CI}=$ 1.020-1.349; $p=0.026$ ) and hyperglycemia (adjusted $\left.\mathrm{OR}^{\gamma}=1.306 ; 95 \% \mathrm{CI}=1.142-1.495 ; p<0.001\right)$ remained to be positively associated with the presence of RE.

In the group with RE, the proportion of LA grade A, $\mathrm{B}$, and $\mathrm{C}$ were $87.03 \% \quad(n=2538), 12.35 \% \quad(n=360)$, $0.62 \%(n=18)$, respectively. There was no participant diagnosed with LA grade D in the present study (Fig. 1). The relationship between the number of MetS components and the severity of RE was analyzed using the chi-square test for trend, as shown in Fig. 2. The trend analysis revealed that the severity of RE was higher as

Table 1 Demographic characteristics and clinical parameters of the study population (continuous variables)

\begin{tabular}{|c|c|c|c|c|c|c|}
\hline \multirow[t]{2}{*}{ Characteristics } & \multicolumn{3}{|c|}{ Reflux esophagitis } & \multicolumn{3}{|c|}{ Without reflux esophagitis } \\
\hline & $N$ & Mean & $S D$ & $N$ & Mean & $S D$ \\
\hline Age (years) & 2916 & 51.20 & 11.14 & 1979 & 48.26 & 11.04 \\
\hline $\mathrm{BMI}\left(\mathrm{kg} / \mathrm{m}^{2}\right)$ & 2916 & 24.64 & 3.54 & 1979 & 23.76 & 3.45 \\
\hline Waist circumference $(\mathrm{cm})$ & 2916 & 82.71 & 9.95 & 1979 & 79.52 & 9.51 \\
\hline $\mathrm{SBP}(\mathrm{mmHg})$ & 2916 & 125.16 & 16.70 & 1979 & 120.96 & 16.72 \\
\hline $\mathrm{DBP}(\mathrm{mmHg})$ & 2916 & 79.77 & 10.14 & 1979 & 77.83 & 9.90 \\
\hline Body fat percentage (\%) & 2673 & 27.19 & 5.50 & 1796 & 27.07 & 5.58 \\
\hline $\mathrm{FPG}(\mathrm{mg} / \mathrm{dL})$ & 2916 & 100.52 & 24.55 & 1979 & 96.87 & 22.24 \\
\hline $\mathrm{HbA} 1 \mathrm{C}(\%)$ & 2747 & 5.59 & 0.89 & 1846 & 5.45 & 0.74 \\
\hline $\mathrm{TC}(\mathrm{mg} / \mathrm{dL})$ & 2916 & 197.59 & 37.56 & 1979 & 196.54 & 35.79 \\
\hline $\mathrm{HDL}-\mathrm{C}(\mathrm{mg} / \mathrm{dL})$ & 2916 & 48.02 & 12.30 & 1979 & 50.05 & 12.94 \\
\hline LDL-C (mg/dL) & 2914 & 122.10 & 32.59 & 1979 & 121.29 & 32.13 \\
\hline $\mathrm{TG}(\mathrm{mg} / \mathrm{dL})$ & 2916 & 130.70 & 88.48 & 1979 & 115.78 & 77.96 \\
\hline Uric acid (mg/dL) & 2863 & 6.27 & 1.48 & 1938 & 5.83 & 1.45 \\
\hline
\end{tabular}

Continuous variables are presented as mean $\pm S D ; B M I$ body mass index, $D B P$ diastolic blood pressure, $F P G$ fasting plasma glucose, $H b A 1 C$ glycosylated hemoglobin, HDL-C high-density lipoprotein cholesterol, $L D L-C$ low-density lipoprotein cholesterol, $N$ number of patients, SD standard deviation, SBP systolic blood pressure, TC Total cholesterol, TG triglycerides 
Table 2 Comparison of associated factors between the participants with and without reflux esophagitis

\begin{tabular}{|c|c|c|c|c|c|c|}
\hline \multirow[t]{2}{*}{ Variables } & & \multirow{2}{*}{$\begin{array}{l}\text { Reflux esophagitis } \\
N(\%)\end{array}$} & \multirow{2}{*}{$\begin{array}{l}\text { Without reflux esophagitis } \\
\text { N (\%) }\end{array}$} & \multicolumn{3}{|c|}{ Univariate logistic regression analysis } \\
\hline & & & & $O R$ & $95 \% \mathrm{Cl}$ & $p$-value \\
\hline \multirow[t]{2}{*}{ Age } & $<65$ years & $2582(58.4)$ & $1839(41.6)$ & 1.000 & & \\
\hline & $\geq 65$ years & $334(70.5)$ & $140(29.5)$ & 1.699 & $1.383-2.088$ & $<0.001^{* *}$ \\
\hline \multirow[t]{2}{*}{ Gender } & Female & $1040(51.1)$ & $996(48.9)$ & 1.000 & & \\
\hline & Male & $1876(65.6)$ & $983(34.4)$ & 1.828 & $1.627-2.053$ & $<0.001^{* *}$ \\
\hline BMI (mean $\pm S D)$ & & $24.64 \pm 3.54$ & $23.76 \pm 3.45$ & 1.076 & $1.058-1.094$ & $<0.001^{* *}$ \\
\hline Uric acid (mean $\pm S D$ ) & & $6.27 \pm 1.48$ & $5.83 \pm 1.45$ & 1.226 & $1.178-1.277$ & $<0.001^{* *}$ \\
\hline \multirow[t]{2}{*}{ Smoking } & No & $2402(57.8)$ & $1753(42.2)$ & 1.000 & & \\
\hline & Yes & $514(69.5)$ & $226(30.5)$ & 1.660 & $1.403-1.964$ & $<0.001^{* *}$ \\
\hline \multirow[t]{2}{*}{ Alcohol consumption } & No & $2196(57.0)$ & $1656(43.0)$ & 1.000 & & \\
\hline & Yes & $720(69.0)$ & $323(31.0)$ & 1.681 & $1.453-1.945$ & $<0.001^{* *}$ \\
\hline \multirow[t]{2}{*}{ Betel nuts chewing } & No & $2833(59.3)$ & $1941(40.7)$ & 1.000 & & \\
\hline & Yes & 83 (68.6) & $38(31.4)$ & 1.496 & $1.015-2.206$ & $0.042^{*}$ \\
\hline \multirow[t]{2}{*}{ Hyperlipidemia history } & No & $304(63.6)$ & $174(36.4)$ & 1.000 & & \\
\hline & Yes & $979(66.1)$ & $501(33.9)$ & 1.118 & $0.902-1.387$ & 0.308 \\
\hline \multirow[t]{2}{*}{ Hypertension history } & No & $2104(57.0)$ & $1586(43.0)$ & 1.000 & & \\
\hline & Yes & $812(67.4)$ & 393 (32.6) & 1.557 & $1.358-1.786$ & $<0.001^{* *}$ \\
\hline \multirow[t]{2}{*}{ Diabetes history } & No & $2480(57.9)$ & $1801(42.1)$ & 1.000 & & \\
\hline & Yes & $436(71.0)$ & $178(29.0)$ & 1.779 & $1.479-2.139$ & $<0.001^{* *}$ \\
\hline \multirow[t]{2}{*}{ Gastric ulcer } & No & $2420(59.4)$ & $1654(40.6)$ & 1.000 & & \\
\hline & Yes & $496(60.4)$ & $325(39.6)$ & 1.043 & $0.895-1.216$ & 0.589 \\
\hline \multirow[t]{2}{*}{ H. pylori infection ${ }^{\#}$} & No & $2758(59.2)$ & $1897(40.8)$ & 1.000 & & \\
\hline & Yes & $158(65.8)$ & $82(34.2)$ & 1.325 & $1.009-1.741$ & $0.043^{*}$ \\
\hline \multirow[t]{2}{*}{ Hiatal hernia } & No & $2853(59.1)$ & $1975(40.9)$ & 1.000 & & \\
\hline & Yes & $63(94.0)$ & $4(6.0)$ & 10.903 & $3.962-30.002$ & $<0.001^{* *}$ \\
\hline \multirow[t]{2}{*}{ Abdominal obesity } & No & $1983(57.1)$ & $1490(42.9)$ & 1.000 & & \\
\hline & Yes & $933(65.6)$ & $489(34.4)$ & 1.434 & $1.261-1.630$ & $<0.001^{* *}$ \\
\hline \multirow[t]{2}{*}{ Elevated TG } & No & 2065 (57.6) & $1521(42.4)$ & 1.000 & & \\
\hline & Yes & $851(65.0)$ & $458(35.0)$ & 1.369 & $1.200-1.561$ & $<0.001^{* *}$ \\
\hline \multirow[t]{2}{*}{ Reduced HDL-C } & No & $1856(58.8)$ & $1302(41.2)$ & 1.000 & & \\
\hline & Yes & $1060(61.0)$ & $677(39.0)$ & 1.098 & $0.975-1.238$ & 0.124 \\
\hline \multirow[t]{2}{*}{ Elevated BP } & No & $1387(54.6)$ & $1152(45.4)$ & 1.000 & & \\
\hline & Yes & $1529(64.9)$ & $827(35.1)$ & 1.536 & $1.369-1.723$ & $<0.001^{* *}$ \\
\hline \multirow[t]{2}{*}{ Hyperglycemia } & No & $1853(56.1)$ & $1449(43.9)$ & 1.000 & & \\
\hline & Yes & $1063(66.7)$ & $530(33.3)$ & 1.568 & $1.384-1.777$ & $<0.001^{* *}$ \\
\hline \multirow[t]{2}{*}{ MetS } & No & $1967(56.2)$ & $1533(43.8)$ & 1.000 & & \\
\hline & Yes & $949(68.0)$ & $446(32.0)$ & 1.658 & $1.455-1.890$ & $<0.001^{* *}$ \\
\hline \multirow[t]{3}{*}{ MetS components } & 0 & $575(50.2)$ & $571(49.8)$ & 1.000 & & \\
\hline & 1 & $729(57.8)$ & $533(42.2)$ & 1.358 & $1.156-1.595$ & $<0.001^{* *}$ \\
\hline & 2 & $663(60.7)$ & $429(39.3)$ & 1.535 & $1.298-1.815$ & $<0.001^{* *}$ \\
\hline
\end{tabular}


Table 2 Comparison of associated factors between the participants with and without reflux esophagitis (Continued)

\begin{tabular}{|c|c|c|c|c|c|c|}
\hline \multirow[t]{2}{*}{ Variables } & & \multirow{2}{*}{$\begin{array}{l}\text { Reflux esophagitis } \\
\text { N (\%) }\end{array}$} & \multirow{2}{*}{$\begin{array}{l}\text { Without reflux esophagitis } \\
N(\%)\end{array}$} & \multicolumn{3}{|c|}{ Univariate logistic regression analysis } \\
\hline & & & & OR & $95 \% \mathrm{Cl}$ & $p$-value \\
\hline & 3 & $533(68.0)$ & $251(32.0)$ & 2.109 & $1.745-2.549$ & $<0.001^{* *}$ \\
\hline & 4 & $298(68.3)$ & $138(31.7)$ & 2.144 & $1.699-2.706$ & $<0.001^{* *}$ \\
\hline & 5 & $118(67.4)$ & $57(32.6)$ & 2.056 & $1.468-2.879$ & $<0.001^{* *}$ \\
\hline
\end{tabular}

OR are calculated by $\mathrm{N}(\%)$ for categorical variables and by mean $\pm S D$ for continuous variables using univariate logistic regression analysis. ${ }^{\#}$ Of the 4895 participants who underwent upper gastrointestinal endoscopy, only 719 received rapid urease tests, 240 of which were positive, which represented positive $H$. pylori infection ${ }^{*} p<0.05 ;{ }^{* *} p<0.001$

$B P$ blood pressure, $\mathrm{Cl}$ confidence interval, $H D L-C$ high-density lipoprotein, $H$. pylori Helicobacter pylori, MetS metabolic syndrome, $N$ number of patients, $O R$ odds ratio, $T G$ triglycerides

the number of MetS components increased $(p<0.001)$. Table 3 also demonstrated that the adjusted odds ratios of RE increased along with the rising number of MetS components, using 0 component as reference (model 1 , Table 3). The results indicated a dose-response relation between the number of MetS components and the presence of RE, which supported the results in the trend analysis.

Take a comprehensive look at the results of model 2 and model 3 , older age ( $\geq 65$ years), male gender, smoking, alcohol consumption, higher BMI, higher uric acid, and hiatal hernia were all found significantly related to RE. Particularly, the presence of hiatal hernia was found to be a strong associated factor for RE.

\section{Discussion}

Same as our initial hypothesis, this cross-sectional population-based study demonstrated that MetS was positively associated with RE. Among the five MetS components, abdominal obesity, elevated BP, hyperglycemia, and elevated TG were independent predictors for RE. Most importantly, this study found a linear trend of association between the number of MetS components and the severity of RE.

Abdominal obesity has been hypothesized to induce gastroesophageal reflux through both mechanical and humoral causes. Abdominal obesity, also called central obesity, is defined as an elevated waist circumference. The significance of an elevated waist circumference is the accumulation of visceral fat. Compared with simple obesity (only defined by $\mathrm{BMI}$ ), visceral fat accumulation is considered to be a stronger risk factor for the development of hypertension, dyslipidemia, diabetes mellitus, coronary artery disease, and cerebrovascular disease [9]. Visceral fat accumulation has also been reported to increase intra-abdominal pressure and transient lower esophageal sphincter relaxation, which can promote gastroesophageal reflux $[9,15,19]$. In addition to mechanical causes, adipose tissues have been shown to overproduce pro-inflammatory cytokines (interleukin-6, tumor necrosis factor- $\alpha$, etc.), which can cause esophageal circular muscle relaxation and insulin resistance $[9,19,24]$. These mechanisms can then lead to chronic inflammation of the gastroesophageal junction and result in the development of RE.
Hypertension has been reported to be significantly associated with RE in several previous studies, which is consistent with the our study $[9,30,31]$, although the mechanism for this relationship remains unclear. Calcium channel blockers are widely used to treat hypertension. Some studies have reported that calcium channel blockers are important associated factors for RE as they inhibit esophageal muscle contraction and reduce lower esophageal sphincter pressure leading to $\operatorname{RE}[9,12,30]$. However, in addition to the side effects of antihypertensive treatment, the influence of hypertension itself must be taken into account. Several studies have suggested that genetic factors may play a role and that environmental factors known to increase blood pressure, such as high salt intake and life stress, may also have an impact on this issue [31]. Since this study is a retrospective cross-sectional study, we did not include environmental factors or exclude the patients using calcium channel blockers in our analysis.

The association between hyperglycemia and RE is controversial. Most previous studies have reported no significant correlation between hyperglycemia and RE [18, 19, 24, 32]. However, an increasing number of studies support a positive relationship between the two diseases $[9,19]$. In our study, hyperglycemia ( $\mathrm{FPG} \geq 100 \mathrm{mg} / \mathrm{dL}$ ) was an independent associated factor for RE. Current studies hypothesized that hyperglycemia causes RE due to diabetic autonomic neuropathy and insulin resistance. Vagus nerve injury, a common complication of diabetes autonomic neuropathy, affects esophageal motor and sensory function. Motor dysfunction of the esophagus includes slower gastric emptying, abnormal esophageal motility, ineffective bolus transport, and more frequent esophageal transient lower esophageal sphincter relaxation $[9,30,33]$. The perceptional abnormalities such as nausea and abdominal fullness, which result from esophageal sensory dysfunction, are important in clinical reflux symptoms [33]. Few studies have discussed the occurrence of RE in patients with impaired fasting glucose or glucose intolerance. Some studies have suggested that a high serum glucose level influences the motor function of the esophagus before the diagnosis of diabetes mellitus was made $[9,34]$. Our study results strengthen the hypothesis that hyperglycemia is associated with the development of RE. 
Table 3 Multivariate logistic regression analysis of associated factors and reflux esophagitis

\begin{tabular}{|c|c|c|c|c|c|c|c|c|c|c|}
\hline \multirow[t]{2}{*}{ Variables } & & \multicolumn{3}{|l|}{ Model 1} & \multicolumn{3}{|l|}{ Model 2} & \multicolumn{3}{|l|}{ Model 3} \\
\hline & & $\overline{\text { Adjusted } O R^{a}}$ & $95 \% \mathrm{Cl}$ & $p$-value & $\overline{\text { Adjusted } O R^{\beta}}$ & $95 \% \mathrm{Cl}$ & $p$-value & Adjusted $O R^{Y}$ & $95 \% \mathrm{Cl}$ & $p$-value \\
\hline \multirow[t]{2}{*}{ Age } & $<65$ years & & & & 1.000 & & & 1.000 & & \\
\hline & $\geq 65$ years & & & & 1.649 & $1.328-2.048$ & $<0.001^{* *}$ & 1.499 & $1.203-1.868$ & $<0.001^{* *}$ \\
\hline \multirow[t]{2}{*}{ Gender } & Female & & & & 1.000 & & & 1.000 & & \\
\hline & Male & & & & 1.317 & $1.136-1.527$ & $<0.001^{* *}$ & 1.345 & $1.159-1.560$ & $<0.001^{* *}$ \\
\hline BMI (mean $\pm S D$ ) & & & & & 1.025 & $1.004-1.047$ & $0.018^{*}$ & & & \\
\hline Uric acid (mean $\pm S D$ ) & & & & & 1.090 & $1.037-1.145$ & $0.001^{*}$ & 1.096 & $1.044-1.151$ & $<0.001^{* *}$ \\
\hline \multirow[t]{2}{*}{ Smoking } & No & 1.000 & & & 1.000 & & & 1.000 & & \\
\hline & Yes & 1.443 & $1.207-1.724$ & $<0.001^{* *}$ & 1.272 & $1.055-1.533$ & $0.012^{*}$ & 1.294 & $1.072-1.561$ & $0.007^{*}$ \\
\hline \multirow[t]{2}{*}{ Alcohol consumption } & No & 1.000 & & & 1.000 & & & 1.000 & & \\
\hline & Yes & 1.382 & $1.183-1.615$ & $<0.001^{* *}$ & 1.286 & $1.092-1.514$ & $0.003^{*}$ & 1.263 & $1.072-1.488$ & $0.005^{*}$ \\
\hline \multirow[t]{2}{*}{ Betel nuts chewing } & No & 1.000 & & & & & & & & \\
\hline & Yes & 1.211 & $0.816-1.795$ & 0.342 & & & & & & \\
\hline \multirow[t]{2}{*}{ Hypertension history } & No & 1.000 & & & & & & & & \\
\hline & Yes & 1.201 & $1.036-1.393$ & $0.015^{*}$ & & & & & & \\
\hline \multirow[t]{2}{*}{ Diabetes history } & No & 1.000 & & & & & & & & \\
\hline & Yes & 1.433 & $1.182-1.736$ & $<0.001^{* *}$ & & & & & & \\
\hline \multirow[t]{2}{*}{ H. pylori infection } & No & 1.000 & & & & & & & & \\
\hline & Yes & 1.174 & $0.890-1.550$ & 0.257 & & & & & & \\
\hline \multirow[t]{2}{*}{ Hiatal hernia } & No & 1.000 & & & 1.000 & & & 1.000 & & \\
\hline & Yes & 8.230 & $2.978-22.745$ & $<0.001^{* *}$ & 7.420 & $2.677-20.567$ & $<0.001^{* *}$ & 7.490 & 2.699-20.786 & $<0.001^{* *}$ \\
\hline \multirow[t]{2}{*}{ Abdominal obesity } & No & 1.000 & & & & & & 1.000 & & \\
\hline & Yes & 1.352 & $1.186-1.542$ & $<0.001^{* *}$ & & & & 1.173 & $1.020-1.349$ & $0.026^{*}$ \\
\hline \multirow[t]{2}{*}{ Elevated TG } & No & 1.000 & & & & & & & & \\
\hline & Yes & 1.171 & $1.022-1.343$ & $0.023^{*}$ & & & & & & \\
\hline \multirow[t]{2}{*}{ Elevated BP } & No & 1.000 & & & & & & 1.000 & & \\
\hline & Yes & 1.197 & $1.056-1.356$ & $0.005^{*}$ & & & & 1.163 & $1.023-1.323$ & $0.021^{*}$ \\
\hline \multirow[t]{2}{*}{ Hyperglycemia } & No & 1.000 & & & & & & 1.000 & & \\
\hline & Yes & 1.306 & $1.144-1.492$ & $<0.001^{* *}$ & & & & 1.306 & $1.142-1.495$ & $<0.001^{* *}$ \\
\hline \multirow[t]{2}{*}{ MetS } & No & 1.000 & & & 1.000 & & & & & \\
\hline & Yes & 1.411 & $1.233-1.616$ & $<0.001^{* *}$ & 1.251 & $1.071-1.462$ & $0.005^{*}$ & & & \\
\hline \multirow[t]{6}{*}{ MetS components } & 0 & 1.000 & & & & & & & & \\
\hline & 1 & 1.175 & $0.996-1.386$ & 0.056 & & & & & & \\
\hline & 2 & 1.209 & $1.014-1.441$ & $0.034^{*}$ & & & & & & \\
\hline & 3 & 1.615 & $1.325-1.968$ & $<0.001^{* *}$ & & & & & & \\
\hline & 4 & 1.603 & $1.259-2.040$ & $<0.001^{* *}$ & & & & & & \\
\hline & 5 & 1.514 & $1.072-2.139$ & $0.018^{*}$ & & & & & & \\
\hline
\end{tabular}

Adjusted $\mathrm{OR}$ are calculated by $\mathrm{N}(\%)$ for categorical variables and by mean $\pm S D$ for continuous variables using multivariate logistic regression analysis. ${ }^{a}$ Each variable was adjusted for age and gender in the model $1 ;{ }^{\beta}$ All variables in the model 2 were controlled by each other; ${ }^{\gamma}$ All variables in the model 3 were controlled by each other

${ }^{*} p<0.05 ;{ }^{* *} p<0.001$

$B M I$ body mass index, $B P$ blood pressure, $C l$ confidence interval, $H$. pylori Helicobacter pylori, MetS metabolic syndrome, $N$ number of patients, $S D$ standard deviation, $O R$ odds ratio, $T G$ triglycerides

A weak association was found between elevated TG and RE after adjusting for age and gender (shown in model 1, Table 3). It has been reported that hypertriglyceridemia may be related to RE in several previous studies [9, 19, 26, 30, 35]. Hypertriglyceridemia is known to be associated with high dietary fat. An excessively high fat diet can result in delayed 
gastric emptying, and further increases the risk of RE [19, 32]. In accordance with our study, most previous studies have not reported a significant association between HDL-C and RE $[10,24,35]$.

The most important result of this study is the positive association between MetS and RE. We further identified a linear trend of correlation between the number of MetS components and the severity of RE. According to multivariate analysis, we also found a dose-response relation between the number of MetS components and the presence of RE (shown in model 1, Table 3).

An increase in the number of MetS components was associated with the presence and a more severe grade of RE. This dose-response relation means that the two diseases are not only related to each other, but also have a degree of influence on each other. As described above, most MetS components have been proven associated with the occurrence of RE. A case-control study in Korea in 2008 identified insulin resistance and MetS as risk factors for RE [24]. Moreover, a cross-sectional study in 2011 reported that insulin resistance was an independent predictor for the prevalence and severity of RE [35]. Insulin resistance is currently known as a core factor in the development of MetS. Therefore, it is possible that MetS is an important predictor for the development of RE. From an another point of view, persistent gastric acid stimulation can result in chronic inflammation of the esophagus, and chronic inflammation has been proven to be an important leading cause of MetS [32]. Therefore, it is also possible that RE leads to the occurrence of MetS. Further prospective longitudinal studies are needed to elucidate which MetS or RE occurs first.
We also found different distributions of several baseline characteristics between the groups with and without RE. The individuals with RE were predominant male and exhibited older age, higher BMI, more smoking, and more alcohol consumption. A longitudinal study in 2008 reported possible spontaneous regression in patients with low-grade RE (LA grade A or B) without pharmacological treatment [15]. Accordingly, patients with low grade RE should be encourage to make lifestyle changes to reverse the disease, such as weight reduction, stop smoking and stop drinking alcohol.

There are several limitations to this study. First, previous studies have reported the prevalence of RE ranged from 9.0 to $24.6 \%$ in a screening health examination in Taiwan [36]. However, there was a particularly high prevalence rate of RE (59.6\%) in our study population. All participants were enrolled from the database of our Health Examination Center, and most of them were able to afford self-paid health examinations, including upper gastrointestinal endoscopy. Although a high socioeconomic status had not been proven to be a causative factor for RE [18], it possibly caused selection bias in our study. Due to the upper gastrointestinal endoscopy was optional, relative invasive and high price, those who already had gastrointestinal symptoms tended to receive it. However, this hypothesis was not confirmed due to lack of asking gastrointestinal symptoms in the initial questionnaire. Overdiagnosis is an another possible explanation of the high prevalence rate of RE in our study population. Most people diagnosed with RE belong to LA grade A (87\%). The diagnostic criteria for LA grade A by each gastroenterologist vary widely and may lead to overdiagnosis. Second, this study did not include the effects of several

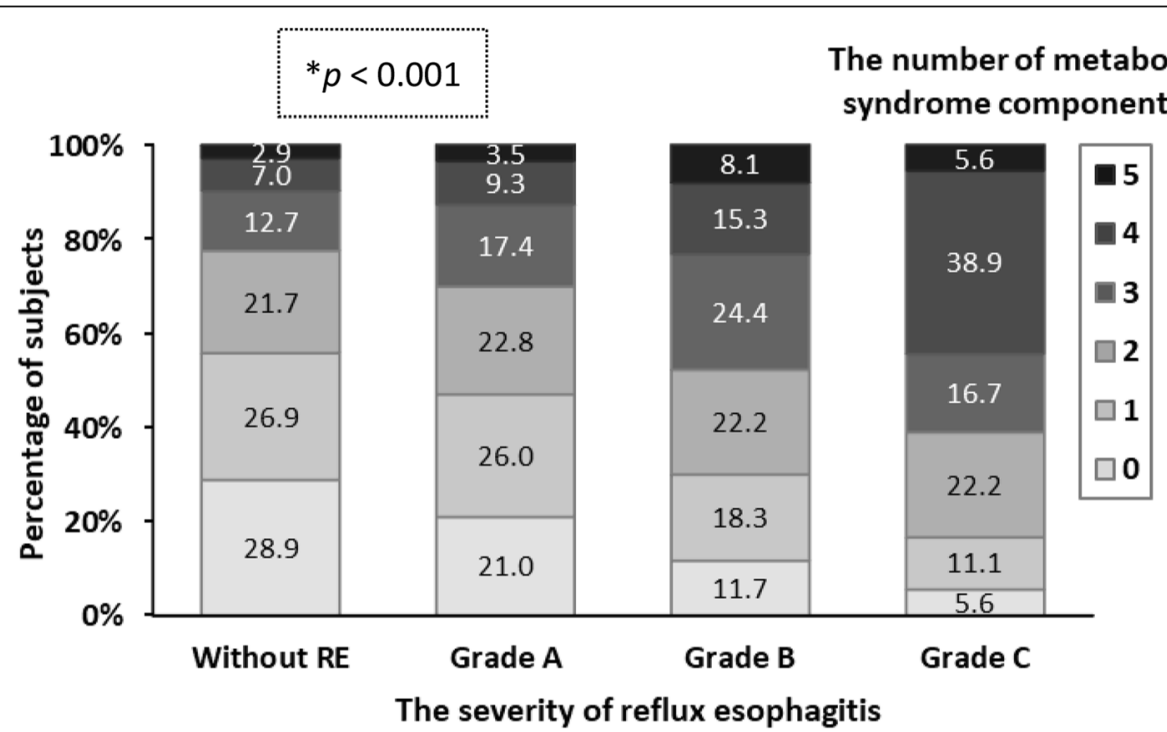

Fig. 2 Trend analysis between the severity of reflux esophagitis and the number of metabolic syndrome components. $p$ value by the chi-square test for trend. ${ }^{*} p<0.001$ 
confounding factors, such as lifestyle and dietary habits, comedications (including aspirin or non-steroid anti-inflammatory drugs, proton-pump inhibitor or histamine- 2 receptor antagonists), and socioeconomic status. Excessive fatty sweat food consumption can also weaken lower esophageal sphincter and cause gastroesophageal reflux [8]. Recent aspirin or non-steroid anti-inflammatory drugs use may increase the risk of reflux esophagitis. Otherwise, taking proton-pump inhibitor or histamine- 2 receptor antagonists may improve reflux esophagitis [12]. Third, self-reported medical and pharmacology history (such as anti-dyslipidemia medicine use) may result in misclassification bias. Fourth, not everyone received a rapid urease test, so there would be misclassification bias.

There are several strengths to this study. To the best of our knowledge, this is the first study to identify the linear trend of an association between the number of MetS components and the severity of RE. In addition, we enrolled a large number of participants. We also focused on a healthy population so we could suggest early prevention measures for the known risk factors.

\section{Conclusion}

In summary, the present study suggests that MetS is significantly associated with the presence and the severity of RE, although the study could not clarify whether MetS or RE occurred first. Therefore, further prospective longitudinal studies are needed to evaluate the association between RE and MetS in the future.

\section{Abbreviations \\ BMl: Body mass index; BP: Blood pressure; DBP: Diastolic blood pressure; FPG: Fasting plasma glucose; H. pylori: Helicobacter pylori; $\mathrm{HbA1C}$ : glycosylated hemoglobin; HDL-C: High-density lipoprotein cholesterol; LA: Los Angeles classification of esophagitis; LDL-C: Low-density lipoprotein cholesterol; MetS: Metabolic syndrome; RE: Reflux esophagitis; SBP: Systolic blood pressure; TC: Total cholesterol; TG: Triglycerides}

\section{Acknowledgements}

The authors would like to thank all the participants in this study. We also thank the members of the Department of Health Evaluation, Changhua Christian Hospital for helping with data collection.

\section{Funding}

This study was supported by the research project of Changhua Christian Hospital, Changhua city, Taiwan (106-CCH-IRP-021). The grant supported data collection and manuscript drafting.

\section{Availability of data and materials}

The datasets used and analyzed during the current study are available from the corresponding author on reasonable request.

\section{Authors' contributions}

ICL proposed the study. Yi HH and ICL performed research, wrote the manuscript and contributed to discussion. Yao HH, MFW, and WCL contributed to the conceptualizing the paper and Literature review. PYY contributed to the study design and data interpretation. Yi HH and YJC collected and analyzed the data. All the authors read and approved the final manuscript.

\section{Ethics approval and consent to participate}

This study was conducted in compliance with the principles of the Declaration of Helsinki, and the protocol was approved by the Ethics Committee of Changhua Christian Hospital, Changhua City, Taiwan (CCH IRB No: 150408). The ethics committee waived the need for informed consent specifically.

\section{Consent for publication}

Not applicable.

\section{Competing interests}

The authors declare that they have no competing interests.

\section{Publisher's Note}

Springer Nature remains neutral with regard to jurisdictional claims in published maps and institutional affiliations.

\section{Author details}

'Department of Family Medicine, Changhua Christian Hospital, No. 135, St. Nan-Xiao, Changhua City 500, Taiwan. ${ }^{2}$ Department of Health Evaluation, Changhua Christian Hospital, Changhua City, Taiwan. ${ }^{3}$ Department of Laboratory, Show Chwan Memorial Hospital, Changhua City, Taiwan.

${ }^{4}$ Department of Rehabilitation, Changhua Christian Hospital, Changhua City, Taiwan. ${ }^{5}$ Changchun Otolaryngeal Clinic, Chiayi City, Taiwan. ${ }^{6}$ Epidemiology and Biostatistics Center, Changhua Christian Hospital, Changhua City, Taiwan. ${ }^{7}$ School of Medicine, Chung Shan Medical University, Taichung City, Taiwan.

${ }^{8}$ School of Medicine, Kaohsiung Medical University, Kaohsiung City, Taiwan.

Received: 17 July 2018 Accepted: 31 January 2019

Published online: 19 February 2019

\section{References}

1. Kang JY, Tay HH, I Y, Guan R, Lim KP, Math MV. Low frequency of endoscopic esophagitis in Asian patients. J Clin Gastroenterol. 1993;16(1):70-3.

2. Goh KL. Gastroesophageal reflux disease in Asia: a historical perspective and present challenges. J Gastroenterol Hepatol. 2011;26(Suppl 1):2-10.

3. Nasseri-Moghaddam S, Razjouyan H, Alimohamadi SM, Mamarabadi M, Ghotbi MH, Mostajabi P, Sohrabpour AA, Sotoudeh M, Abedi B, Mofid A, et al. Prospective acid reflux study of Iran (PARSI): methodology and study design. BMC Gastroenterol. 2007;7:42

4. Vakil N, van Zanten SV, Kahrilas P, Dent J, Jones R, Global Consensus G. The Montreal definition and classification of gastroesophageal reflux disease: a global evidence-based consensus. Am J Gastroenterol. 2006;101(8):1900-20 quiz 1943.

5. Katz $\mathrm{PO}$, Gerson LB, Vela MF. Guidelines for the diagnosis and management of gastroesophageal reflux disease. Am J Gastroenterol. 2013;108(3):308-28 quiz 329.

6. lerardi E, Rosania R, Zotti M, Principe S, Laonigro G, Giorgio F, de Francesco V, Panella C. Metabolic syndrome and gastro-esophageal reflux: a link towards a growing interest in developed countries. World J Gastrointest Pathophysiol. 2010;1(3):91-6.

7. Dodds WJ, Hogan WJ, Helm JF, Dent J. Pathogenesis of reflux esophagitis. Gastroenterology. 1981;81:376-94.

8. Lenglinger J, Riegler M, Schoppmann SF. Gastroesophageal reflux disease and metabolic syndrome. Intern Med. 2012;51(20):2993-3.

9. Moki F, Kusano M, Mizuide M, Shimoyama Y, Kawamura O, Takagi H, Imai T, Mori M. Association between reflux oesophagitis and features of the metabolic syndrome in Japan. Aliment Pharmacol Ther. 2007;26(7):1069-75.

10. Ze EY, Kim BJ, Kang H, Kim JG. Abdominal visceral to subcutaneous adipose tissue ratio is associated with increased risk of erosive esophagitis. Dig Dis Sci. 2017:62(5):1265-71.

11. Niigaki M, Adachi K, Hirakawa K, Furuta K, Kinoshita Y. Association between metabolic syndrome and prevalence of gastroesophageal reflux disease in a health screening facility in Japan. J Gastroenterol. 2013;48(4):463-72.

12. Mohammadi M, Ramezani Jolfaie N, Alipour R, Zarrati M. Is metabolic syndrome considered to be a risk factor for gastroesophageal reflux disease (non-erosive or erosive esophagitis)?: a systematic review of the evidence. Iran Red Crescent Med J. 2016:18(11):e30363.

13. Wong BC, Kinoshita Y. Systematic review on epidemiology of gastroesophageal reflux disease in Asia. Clin Gastroenterol Hepatol. 2006; 4(4):398-407.

14. Goh KL. Obesity and increasing gastroesophageal reflux disease in Asia. J Gastroenterol Hepatol. 2007;22(10):1557-8. 
15. Lee YC, Yen AM, Tai JJ, Chang SH, Lin JT, Chiu HM, Wang HP, Wu MS, Chen $\mathrm{TH}$. The effect of metabolic risk factors on the natural course of gastrooesophageal reflux disease. Gut. 2009;58(2):174-81.

16. El-Serag HB, Ergun GA, Pandolfino J, Fitzgerald S, Tran T, Kramer JR. Obesity increases oesophageal acid exposure. Gut. 2007;56(6):749-55.

17. Watanabe S, Hojo M, Nagahara A. Metabolic syndrome and gastrointestinal diseases. J Gastroenterol. 2007;42(4):267-74.

18. Chung SJ, Kim D, Park MJ, Kim YS, Kim JS, Jung HC, Song IS. Metabolic syndrome and visceral obesity as risk factors for reflux oesophagitis: a crosssectional case-control study of 7078 Koreans undergoing health check-ups. Gut. 2008:57(10):1360-5.

19. Loke SS, Yang KD, Chen KD, Chen JF. Erosive esophagitis associated with metabolic syndrome, impaired liver function, and dyslipidemia. World J Gastroenterol. 2013;19(35):5883-8.

20. Tai CM, Lee YC, Tu HP, Huang CK, Wu MT, Chang CY, Lee CT, Wu MS, Lin JT, Wang WM. The relationship between visceral adiposity and the risk of erosive esophagitis in severely obese Chinese patients. Obesity (Silver Spring). 2010;18(11):2165-9.

21. Grundy SM, Cleeman JI, Daniels SR, Donato KA, Eckel RH, Franklin BA, Gordon DJ, Krauss RM, Savage PJ, Smith SC Jr, et al. Diagnosis and management of the metabolic syndrome: an American Heart Association/ National Heart, Lung, and Blood Institute scientific statement. Circulation. 2005;112(17):2735-52.

22. International Diabetes Federation. The IDF Consensus worldwide definition of the metabolic syndrome. 2006.

23. Despres JP, Lemieux I, Bergeron J, Pibarot P, Mathieu P, Larose E, RodesCabau J, Bertrand OF, Poirier P. Abdominal obesity and the metabolic syndrome: contribution to global cardiometabolic risk. Arterioscler Thromb Vasc Biol. 2008;28(6):1039-49.

24. Park JH, Park DIL, Kim HJ, Cho YK, Sohn CIL, Jeon WK, Kim BI. Metabolic syndrome is associated with erosive esophagitis. World J Gastroenterol. 2008;14(35):5442-7.

25. Wu P, Ma L, Dai GX, Chen Y, Tong YL, Wang C, Yao LW, Jiang YX, Xu SC, A ZS. The association of metabolic syndrome with reflux esophagitis: a casecontrol study. Neurogastroenterol Motil. 2011;23(11):989-94.

26. Lee SW, Lien HC, Chang CS, Lee TY, Peng YC, Yeh HZ. Association of metabolic syndrome with erosive esophagitis and Barrett's esophagus in a Chinese population. J Chin Med Assoc. 2017;80(1):15-8

27. Sogabe M, Okahisa T, Kimura T, Okamoto K, Miyamoto H, Muguruma N, Takayama T. Influence of metabolic syndrome on upper gastrointestinal disease. Clin J Gastroenterol. 2016;9(4):191-202.

28. World Health Organization. Waist circumference and waist-hip ratio: report of a WHO expert consultation. Geneva: World Health Organization; 2008

29. Armstrong D, Bennett JR, Blum AL, Dent J, Dombal FTD, Galmiche JP, Lundell L, Margulies M, Richter JE, Spechler SJ, et al. The endoscopic assessment of esophagitis: a Progress report on observer agreement. Gastroenterology. 1996;111:85-92

30. Song HJ, Shim KN, Yoon SJ, Kim SE, Oh HJ, Ryu KH, Ha CY, Yeom HJ, Song $J \mathrm{H}$, Jung SA, et al. The prevalence and clinical characteristics of reflux esophagitis in koreans and its possible relation to metabolic syndrome. J Korean Med Sci. 2009;24(2):197-202.

31. Gudlaugsdottira S, Verschuren WMM, Dees J, Stijnen T, Wilsona JHP. Hypertension is frequently present in patients with reflux esophagitis or Barrett's esophagus but not in those with non-ulcer dyspepsia. Eur J Intern Med. 2002;13:369-75.

32. Chua CS, Lin YM, Yu FC, Hsu YH, Chen JH, Yang KC, Shih CH. Metabolic risk factors associated with erosive esophagitis. J Gastroenterol Hepatol. 2009; 24(8):1375-9.

33. Rayner CK, Samsom M, Jones KL, Horowitz M. Relationships of upper gastrointestinal motor and sensory function with glycemic control. Diabetes Care. 2001;24:371-81.

34. Fraser R, Horowitz M, Dent J. Hyperglycaemia stimulates pyloric motility in normal subjects. Gut. 1991;32:475-8,

35. Hsu CS, Wang PC, Chen JH, Su WC, Tseng TC, Chen HD, Hsiao TH, Wang CC, $\mathrm{Lin} H \mathrm{H}$, Shyu RY, et al. Increasing insulin resistance is associated with increased severity and prevalence of gastro-oesophageal reflux disease. Aliment Pharmacol Ther. 2011;34(8):994-1004.

36. Chang $\mathrm{CH}$, Wu CP, Wang JD, Lee SW, Chang CS, Yeh HZ, Ko CW, Lien HC. Alcohol and tea consumption are associated with asymptomatic erosive esophagitis in Taiwanese men. PLoS One. 2017;12(3):e0173230.

Ready to submit your research? Choose BMC and benefit from:

- fast, convenient online submission

- thorough peer review by experienced researchers in your field

- rapid publication on acceptance

- support for research data, including large and complex data types

- gold Open Access which fosters wider collaboration and increased citations

- maximum visibility for your research: over $100 \mathrm{M}$ website views per year

At $\mathrm{BMC}$, research is always in progress.

Learn more biomedcentral.com/submissions 